\title{
Slit2 and Robo1 induce opposing effects on metastasis of hepatocellular carcinoma Sk-hep-1 cells
}

\author{
MINGJING YUAN ${ }^{1,2^{*}}$, HUI GUO ${ }^{1 *}$, JING LI $^{1,3^{*}}$, CHENGZHI SUI $^{4}$, YING QIN $^{1}$, JINGJING WANG $^{1}$, \\ YASIR HAYAT KHAN ${ }^{1}$, LIYING YE ${ }^{1}$, FUAN XIE ${ }^{1}$, HENG WANG $^{1}$, LI YUAN ${ }^{1}$ and JUN YE ${ }^{1}$ \\ ${ }^{1}$ State Key Laboratory of Cellular Stress Biology, School of Life Sciences, Xiamen University, Xiamen, Fujian; \\ ${ }^{2}$ 3D Medicine Inc., Shanghai; ${ }^{3}$ Xiamen Haicang Experimental Middle School, Xiamen, Fujian; \\ ${ }^{4}$ The First Affiliated Hospital of Xiamen University, Xiamen, Fujian, P.R. China
}

Received February 3, 2016; Accepted March 28, 2016

DOI: 10.3892/ijo.2016.3506

\begin{abstract}
The neural guidance molecular, Slit2, and its cognate receptor, Robo1, play critical roles in the development of the nervous system, nevertheless, their functions are not limited to this system. Numerous studies have shown decreased Slit2 expression in a wide variety of cancers, highlighting its potential as a tumor suppressor. However, the Slit2/Robol signaling axis was reported to induce either suppressive or stimulatory effects on tumor growth and metastasis, depending on cellular context. There is a paucity of information on the effects of the Slit2/Robo1 signaling axis on the growth and metastasis of human hepatocellular carcinoma (HCC). Large-scale data mining of the Oncomine database has revealed heterogeneous expression of Slit2 in HCC. We screened the Sk-hep-1, a cell line showing a relatively high level of Slit2, and low level of Robol expression. After Slit 2 knockdown and Robol overexpression in these cells, we found Slit2 and Robol exerted opposing effects on tumor growth and metastasis both in in vitro and in vivo models. Slit2 knockdown and Robol overexpression in Sk-hep-1 cells promoted tumor growth and metastasis, suggesting a negative and positive role for Slit2 and Robol, respectively, in tumor progression. Robol overexpression upregulated matrix metalloproteinase (MMP)2, -9 and membrane-type1 MMP (MT1-MMP) expression, stimulated MMP2, but not MMP9 activation, and downregulated expression of TIMP1 and 2. The PI3K/Akt signaling pathway is of importance in regulating MMP2 expression in Sk-hep-1 cells, since Robol overexpression stimulated phosphorylation of Akt
\end{abstract}

Correspondence to: Professor Jun Ye or Professor Li Yuan, State Key Laboratory of Cellular Stress Biology, School of Life Sciences, Xiamen University, Xiamen, Fujian, P.R. China

E-mail: jye@xmu.edu.cn

E-mail: yuanli@xmu.edu.cn

*Contributed equally

Key words: hepatocellular carcinoma, tumor metastasis, Slit2, Robo1, MMP2, PI3k/Akt while the PI3K inhibitor LY294002, significantly inhibited the upregulation of MMP2 and also the enhanced cell invasion induced by Robol overexpression. We postulate that Robol promotes tumor invasion partly by the upregulation of MMP2 after activation of PI3K/Akt signaling pathway. Notably, Slit2 knockdown caused the upregulation of Robol expression both at the mRNA and protein levels. Thus, the stimulatory effects of Slit 2 knockdown on tumor progression can be ascribed, at least in part, to the upregulation of Robol and its positive role in tumor progression.

\section{Introduction}

Slits (Slit1-3) proteins and their cognate receptors (Robo1-4) were originally identified as key regulators in neural development, yet, their functions are not limited to neurons. The Slit/Robo signaling pathway also functions in the development of the heart (1), gonad (2), follicle (3) and kidney (4). Altered expression of Slits and Robo is common in various pathological conditions, particularly in cancer. Current research on the Slit/Robo signaling pathway in tumors is focused on growth and metastasis, of which the Slit2/Robol signaling axis is the most studied. Numerous studies demonstrate that Slit2 exerts its functions through binding to the Robol receptor. This induces controversial effects on two aspects of tumor cells, by either promoting or suppressing tumor growth and on metastasis, depending on cancer types. While the Slit2/Robol signaling axis suppressed growth or metastasis in breast cancer $(5,6)$, pancreatic ductal adenocarcinoma (7), intrahepatic cholangiocarcinoma (8), medulloblastoma (9), and glioma (10-12), it promoted growth and metastasis in intestinal cancer (13), colorectal carcinoma (14), pancreatic islet tumors (15), and chemically-induced squamous cell carcinoma (16). These results underline the multiple effects of Slit2/Robo1 signal pathway on tumor progression.

For tumor metastasis to occur, tumor cells must degrade the extracellular matrix and basement membrane to facilitate invasion. MMPs, in particular, MMP2 and MMP9 are thought to play a critical role in this process. To date, very few studies have reported on the effect of the Slit2/Robo1 signaling pathway on MMP2 and MMP9 expression. In Slit2-transgenic mice, MMP2, but not MMP9 expression 
was upregulated in chemically-induced skin tumors (17). Moreover, a Robol blocking monoclonal antibody inhibited the activity of MMP2 and MMP9 in tongue cancer cells (18). Conversely, Slit2 inhibited the CXCL12-induced activities of MMP2 and MMP9 in breast cancer cells (19). These results suggest that Slit 2 could have both inhibitory and stimulatory effects on MMP2 and MMP9 expression and activity in different tumors. However, how the Slit2/Robo1 signaling pathway modulates MMP2 and MMP9 expression and activity currently remains unknown.

Although the effects of the Slit2/Robol signaling axis on tumor growth and metastasis have been reported in various cancers, very little is known of this pathway in hepatocellular carcinoma (HCC). In the present study, we first examined the expression of Slit2 and Robol in several HCC cell lines, and then, explored the effects of Slit2/Robol on tumor growth and metastasis of cells by lentivirus-mediated Slit2 RNA knockdown and Robol overexpression. We found that, unlike the previously reported either inhibitory or promoting effects of the Slit2/Robol signaling axis on tumor growth and metastasis, Slit 2 and Robol induced opposing effects on these tumor characteristics.

\section{Materials and methods}

Cell lines, vector constructs and reagents. All HCC cell lines, Sk-hep-1, SMMC-7721, HepG2 and normal hepatic cell lines L-O2 were cultured in high-glucose Dulbecco's modified Eagle's medium (DMEM; HyClone Laboratories, Logan, UT, USA) supplemented with $10 \%$ fetal bovine serum (FBS; Gibco-BRL, Carlsbad, CA, USA). The human full length cDNA of Robol (4824 bp) was supplies by Professor Jiahuai Han (State Key Laboratory of Cellular Stress Biology, School of Life Sciences, Xiamen University, Xiamen, China) and subcloned into the lentiviral expression vector pBobi (gift from Professor Jiahuai Han) with a cMyc tag at the carboxyl terminus. Small haipin RNA (shRNA) oligos directed against Slit2 which were designed and screened with online service (http:// katahdin.cshl.org/siRNA/RNAi.cgi?type $=$ shRNA), were annealed and cloned into the lentivirus vector pll3.7 (State Key Laboratory of Cellular Stress Biology, School of Life Sciences). MAPK inhibitors, SB203580, PD98059, SP600125 and PI3K inhibitor, LY294002, were purchased from Calbiochem (San Diego, CA, USA).

Establishment of stable cell lines. Virus stocks were prepared by co-transfecting pll3.7 or pBobi (cMyc tag) with two packaging plasmids (pHR and pVSVG) into 293T cells. Viral supernatants were harvested after $48 \mathrm{~h}$, filtered and centrifuged $(90 \mathrm{~min}$ at $75,000 \mathrm{x}$ g). For Slit 2 RNA knockdown, cell lines were infected with pll3.7-Slit2-shRNA in the presence of polybrene ( $8 \mu \mathrm{g} / \mathrm{ml}$; Sigma, St. Louis, MO, USA) for 2 days. Infected cells were screened by G418 $(1,500 \mu \mathrm{g} / \mathrm{ml}$ for Sk-hep-1; Sigma) treatment. The same pll3.7 vectors with scramble sequence of Slit 2 were used as a control (pll3.7-Slit2shctrl). For Robol overexpression, the method is the same as mentioned above, except cell lines were infected with pBobiRobo1, and screened by puromycin $(2.5 \mu \mathrm{g} / \mathrm{ml}$; Sigma), the same vector encoding GFP was used as a control (pBobi-GFP). Stable transfectants were assayed for the expression of Slit2 and Robol by real-time quantitative PCR (qPCR) and western blot analysis.

PCR. Real-time qPCR and primers used were previously described (20). For reverse transcription PCR (RT-PCR), amplification conditions were initial denaturation at $95^{\circ} \mathrm{C}$ for $1 \mathrm{~min}$, followed by 32 cycles of $95^{\circ} \mathrm{C}$ for $30 \mathrm{sec}, 58^{\circ} \mathrm{C}$ for $30 \mathrm{sec}$ and $72^{\circ} \mathrm{C}$ for $1 \mathrm{~min}$ for MMPs and TIMPs, by 23 cycles and the same conditions for GAPDH. All primer sequences are listed in Table I.

Enzyme-linked immunosorbent assay. A total of $1 \times 10^{6}$ cells were seeded per well in 6-well microplates (Shanghai Sunub Bio-Tech Development, Inc., Shanghai, China). After cells became attached ( $8 \mathrm{~h}$ later), the culture medium was replaced with $2 \mathrm{ml}$ serum-free fresh DMEM/well. Twenty-four hours later, culture supernatants were collected and centrifuged to remove cell debris. Secreted Slit2 production in supernatants was measured by Enzyme-linked immunosorbent assay (ELISA) kit (EIAab, \#E06 $72 \mathrm{~h}$ ) in accordance with the manufacturer's instructions. Optical densities of supernatants were measured at $450 \mathrm{~nm}$ in a microplate reader (MultiSkan MK3; Thermo Fifher Scientific, Waltham, MA, USA).

Cell proliferation, migration and invasion assay. Cell proliferation, migration and invasion assays were performed as previously described (20). Briefly, a total of 500 cells were seeded per well in 96-well microplates (Shanghai Sunub Bio-Tech Development) and cultured for 4 consecutive days. The medium was changed every other day. On each day, one group of culture media was replaced with $100 \mu \mathrm{l}$ serum-free fresh medium containing 10\% MTT (Sigma) and maintained at $37^{\circ} \mathrm{C}$ for $4 \mathrm{~h}$. After discarding the medium, $150 \mu \mathrm{l}$ of DMSO was added to each well to dissolve MTT formazans. Optical densities were measured at $560 \mathrm{~nm}$ with a reference wavelength at $630 \mathrm{~nm}$.

For cell migration, cells that were $90 \%$ confluent in a $24-$ well plate (Shanghai Sunub Bio-Tech Development) were scratched with a 200- $\mu$ l pipette tip to form wounded gaps. After washing out cell debris, the wounded gaps were photographed under a microscope at $x 40$ magnification to acquire a baseline image. Cells were then cultured in DMEM containing 10\% FBS for $24 \mathrm{~h}$ and photographed to obtain the second set of images. Gap width was measured by Image-Pro Plus 6.0 software. Cell migration was quantitatively analyzed by subtracting the gap width of the second image from the baseline image.

For cell invasion, chambers (8 $\mu \mathrm{m}$; Millipore, Billerica, MA, USA) were coated with $20 \mu \mathrm{l}$ diluted Matrigel $(0.1 \mathrm{mg}$ protein $/ \mathrm{ml}$; BD Biosciences) for $30 \mathrm{~min}$ at $37^{\circ} \mathrm{C}$ and inserted into a 24 -well plate. A total of $1 \times 10^{4}$ cells/chamber in $100 \mu 1$ serum-free DMEM were plated on the upper side of Matrigelcoated Transwell chambers. Medium in the lower chambers contained $10 \%$ FBS as the source of chemo-attractants. The plates were incubated for $24 \mathrm{~h}$ at $37^{\circ} \mathrm{C}$. Cells that had invaded the lower surface at $37^{\circ} \mathrm{C}$ were fixed with methanol and stained with crystal violet. Three random fields were counted under a light microscope.

Cell adhesion assay. Twenty-four-well plates were pre-coated with $0.2 \%$ gelatin. Cells were then plated on coated culture 
Table I. Primers for reverse transcriptional PCR.

Primers

$\begin{array}{ll}\text { hMMP1-Forward } & \text { 5'-CATCCAAGCCATATATGGACGTTCC-3' } \\ \text { hMMP1-Reverse } & \text { 5'-TCTGGAGAGTCAAAATTCTCTTCGT-3' } \\ \text { hMMP2-Forward } & \text { 5'-TTTGACGGTAAGGACGGACTC-3' } \\ \text { hMMP2-Reverse } & \text { 5'-TTGGTGTAGGTGTAAATGGGTG-3' } \\ \text { hMMP3-Forward } & \text { 5'-TCAGTCCCTCTATGGACCTC-3' } \\ \text { hMMP3-Reverse } & \text { 5'-GAGGGAAACCTAGGGTGTGG-3' } \\ \text { hMMP8-Forward } & \text { 5'-AGTGCCTGACAGTGGTGGTTTT-3' } \\ \text { hMMP8-Reverse } & \text { 5'-CCAGTAGGTTGG ATAGGGTTGC-3' } \\ \text { hMMP9-Forward } & \text { 5'-CGGAGCACGGAGACGGGTAT-3' } \\ \text { hMMP9-Reverse } & \text { 5'-GCCGCCACGAGGAACAAACT-3' } \\ \text { hMMP10-Forward } & \text { 5'-AGTTTGGCTCATGCCTACCC-3' } \\ \text { hMMP10-Reverse } & \text { 5'-GGCCCAGAACTCATTTCCTTT-3' } \\ \text { hMMP11-Forward } & \text { 5'-GGTGGCAGCCCATGAATTTG-3' } \\ \text { hMMP11-Reverse } & \text { 5'-ACTGAGCACCTTGGAAGAACC-3' } \\ \text { hMMP13-Forward } & \text { 5'-TGGAATTAAGGAGCATGGCG-3' } \\ \text { hMMP13-Reverse } & \text { 5'-CCTCGGAGACTGGTAATGGC-3' } \\ \text { hMT1-MMP-Forward } & \text { 5'-AGGTGATCATCATTGAGGTGG-3' } \\ \text { hMT1-MMP-Reverse } & \text { 5'-ACAGAGAGAAGCAAGGAGGC-3' } \\ \text { hTIMP1-Forward } & \text { 5'-TGCACCTGTGTCCCACCCCACCCACAGACG-3' } \\ \text { hTIMP1-Reverse } & \text { 5'-GGCTATCTGGGACCGCAGGGACTGCCAGGT-3' } \\ \text { hTIMP2-Forward } & \text { 5'-AGGGCCAAAGCGGTCAGT-3' } \\ \text { hTIMP2-Reverse } & \text { 5'-CCTGCTTATGGGTCCTCGA-3' } \\ \text { hGAPDH-Forward } & \text { 5'-ACCACAGTCCATGCCATCAC-3' } \\ \text { hGAPDH-Reverse } & \text { 5'-TCCACCACCCTGTTGCTGTA-3' } \\ & \end{array}$

plates and incubated for 30 min. After medium and nonadherent cells were removed, adherent cells were washed with PBS two times, and stained with crystal violet. After being washed twice, the adherent cells were counted by counting the cell numbers on eight random fields.

Gelatin zymography. Gelatin zymography was performed as previously described (20). A total of 2 million cells were cultured in a $6-\mathrm{cm}$ dish (Shanghai Sunub Bio-Tech Development) with $5 \mathrm{ml}$ DMEM (10\% FBS) for $8 \mathrm{~h}$. Medium was replaced with 2-ml serum-free DMEM and incubated for an additional $12 \mathrm{~h}$. The conditioned medium was collected and filtered through a $0.22-\mu \mathrm{m}$ filter (Millipore). A total of $10 \mu \mathrm{l}$ of conditioned media was mixed with $10 \mu \mathrm{l}$ sample buffer (0.25 M Tris- $\mathrm{HCl}, \mathrm{pH} 6.0,8.5 \%$ glycerol, $4 \%$ sodium dodecyl sulfate and $0.01 \%$ bromophenol blue) and electrophoresed in a $7.5 \%$ SDS-polyacrylamide gel containing $2 \mathrm{mg} / \mathrm{ml}$ gelatin (Sigma). After electrophoresis, the gel was washed three times for $10 \mathrm{~min}$ in $2.5 \%$ Triton $\mathrm{X}-100$ and placed in incubation buffer $\left(50 \mathrm{mM}\right.$ Tris- $\mathrm{HCl}, \mathrm{pH} 7.6,10 \mathrm{mM} \mathrm{CaCl}_{2}, 50 \mathrm{mM} \mathrm{NaCl}$ and $0.05 \%$ Brij-35) overnight at $37^{\circ} \mathrm{C}$. After incubation, the gel was stained with a solution of $0.25 \%$ Coomassie blue R250, $40 \%$ methanol and $10 \%$ acetic acid for $1 \mathrm{~h}$ at room temperature and destained with $40 \%$ methanol and $10 \%$ acetic acid until protein bands were apparent.
Western blot analysis. Western blot analysis was performed as previously described (20). A total of $50 \mu \mathrm{g}$ of protein samples were examined for each protein. After electrophoresis and membrane transfer, the membranes were incubated with rabbit polyclonal primary antibody for Robo1 (\#ab7279; Abcam) at a 1:1,000 dilution, rabbit polyclonal primary antibody Akt (\#9272; Cell Signaling Technology), phospho-Akt (\#9271; Cell Signaling Technology) at a 1:1,000 dilution, mouse monoclonal antibody for $\alpha$-tubulin (\#T6074; Sigma) at a 1:4,000 dilution and appropriate horseradish peroxidaselinked secondary antibodies at a 1:2,000 dilution. After washing three times with TBST, bound antibody was developed using the ECL plus Western Blotting Detection system (Thermo Fisher Scientific).

In vivo tumor growth. Cells $\left(2 \times 10^{7}\right.$ cells $\left./ \mathrm{ml}\right)$ were suspended in PBS, and a $0.1 \mathrm{ml}$ of suspension was inoculated subcutaneously (s.c.) into the right flanks of 4-week-old Balb/c nude mice on day 0 . All animals were sacrificed after 30 days, the resulting tumors were completely dissected, and then the tumor volumes calculated using the formula (length $\mathrm{x}$ width) ${ }^{2} / 2$.

Experimental metastasis. Cells (2x10\%/mouse) in $0.1 \mathrm{ml}$ of PBS were injected into 4-week-old Balb/c nude mice through the tail vein. All animals were sacrificed after 30 days. The lungs 


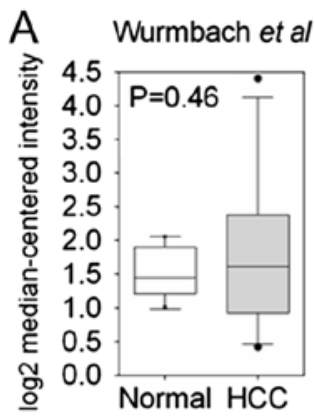

B Wurmbath et al



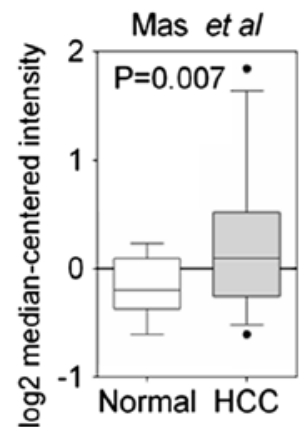

Mas et al

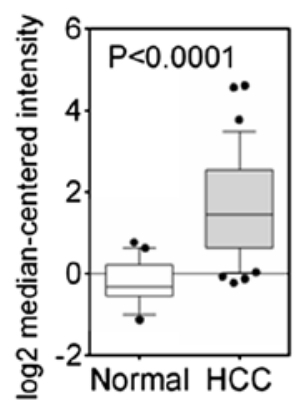

Roessler et al

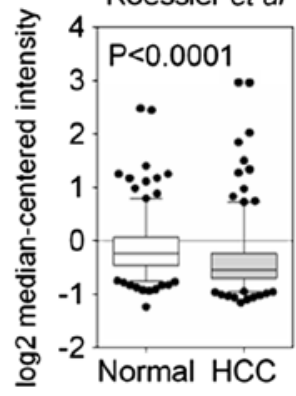

Roessler et al

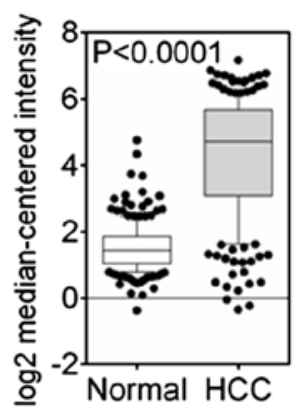

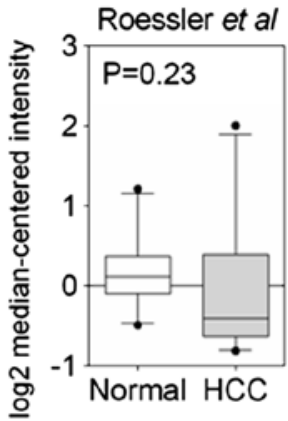

Roessler et al

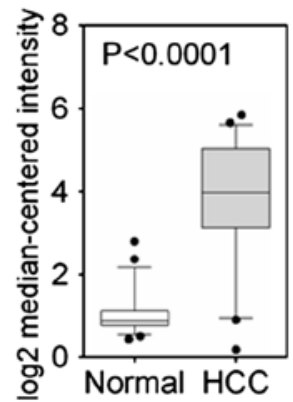

Figure 1. Oncomine data analysis. Slit2 is heterogeneously expressed, while Robol is markedly elevated in HCC. The original data for the microarray analysis of Slit2 and Robol from different published reports was extracted from Oncomine database. The box plot shows the 25th and 75th percentiles as the bottom and top boundaries of the box, respectively. The line within the box represents the median, and the whiskers above and below the box indicate the 90 th and 10th percentiles.

were first dissected and visible tumor nodules in all lung lobes counted using a stereo fluorescence microscope. Nodules were then fixed in $4 \%$ paraformaldehyde (PAF) solution, embedded in paraffin, sectioned and stained with hematoxylin and eosin (H\&E) for routine histological examination by light microscopy.

Statistical analysis. Statistical analysis was carried out using GraphPad Prism 5 software (GraphPad Software, Inc., Irvine, CA, USA) and depicted as mean \pm SD or SEM. Student's t-test or the two-way analysis of variance (ANOVA) were performed and $\mathrm{P}<0.05$ was considered statistically significant.

\section{Results}

Slit2 is heterogeneously expressed in HCC. Jin et al (21) reported the epigenetic inactivation of Slit 2 in 6 of $8 \mathrm{HCC}$ cell lines and 45 of 54 tumor tissues. To extend our understanding of Slit 2 expression in HCC samples on a large-scale, we explored the Slit 2 expression using an Oncomine database. Data mining revealed a heterogeneous expression pattern of Slit2 in HCC samples (22-24). As shown in Fig. 1A, only one analysis showed significantly reduced Slit 2 expression compared to normal tissues (24), suggesting that the observed reduction in Slit2 expression does not apply to all HCC samples. In contrast, the expression of Robol was markedly elevated in HCC samples (Fig. 1B). To verify the results in HCC cell lines, we contrasted Slit 2 and Robol gene expression in 3 commonly used HCC cell lines to those of a normal hepatic cell line, L-O2 by real-time qPCR. As shown in Fig. 2A, compared to L-O2, Hep3B cells showed a comparable level of Slit2 expression to L-O2, and reduced Slit2 expres- sion was observed in HepG2 cells. However, Sk-hep-1 cells showed elevated Slit2 expression relative to L-O2 ( $\mathrm{P}=0.0016$, $\mathrm{n}=3$ ). Robol expression in Sk-hep-1 was comparable to that of L-O2, while Hep3B and HepG2 cells maintained a markedly elevated Robol expression level. Sk-hep-1 cells were selected for further study by establishing the stable Slit 2 knockdown or Robol-overexpressing cell lines. Furthermore, to understand the expression of other slit ligands and Robo receptors in Sk-hep-1 cells, the expression of Slit 3 and Robo2, 3 and 4 were compared to that of Slit2 or Robol, respectively. As shown in Fig. 2C, the expression of Slit3 was nearly 5-fold greater than that of Slit2 in Sk-hep-1 cells, indicating a potentially important role for Slit3 in Sk-hep-1 cells. Robo4 was slightly less expressed compared with Robo1, while Robo2 and Robo3 expression levels were extremely low (Fig. 2D).

Generation of stable Slit2 knockdown and Robol overexpressing cell lines. Sk-hep-1 cells were transduced with a VSV-G pseudotyped lentivirus vector (pl13.7) for stable Slit2 knockdown (Sk-Slit2-shRNA), and with a pBobi vector for stable Robol overexpression (Sk-Robol). The efficiency of gene knockdown and overexpression were assayed at both mRNA and protein levels. Slit2 expression in Sk-hep-1 cells was significantly decreased when transduced with two pll3.7 vectors containing Slit2-shRNA, with knockdown efficiencies of 55 and $60 \%$ for Slit2 in Sk-hep-1 cells (Fig. 3A), respectively. These mRNA results were further confirmed at the protein level. As Slit2 is a secreted soluble protein, an ELISA assay was performed to examine changes in Slit2 proteins in the supernatant of Sk-hep-1 cells. The concentration of Slit2 in the supernatant of Sk-Slit2-shctrl cells was $2.26 \mathrm{ng} / \mathrm{ml}$ $(n=3)$. After Slit2 mRNA knockdown, the concentration of 

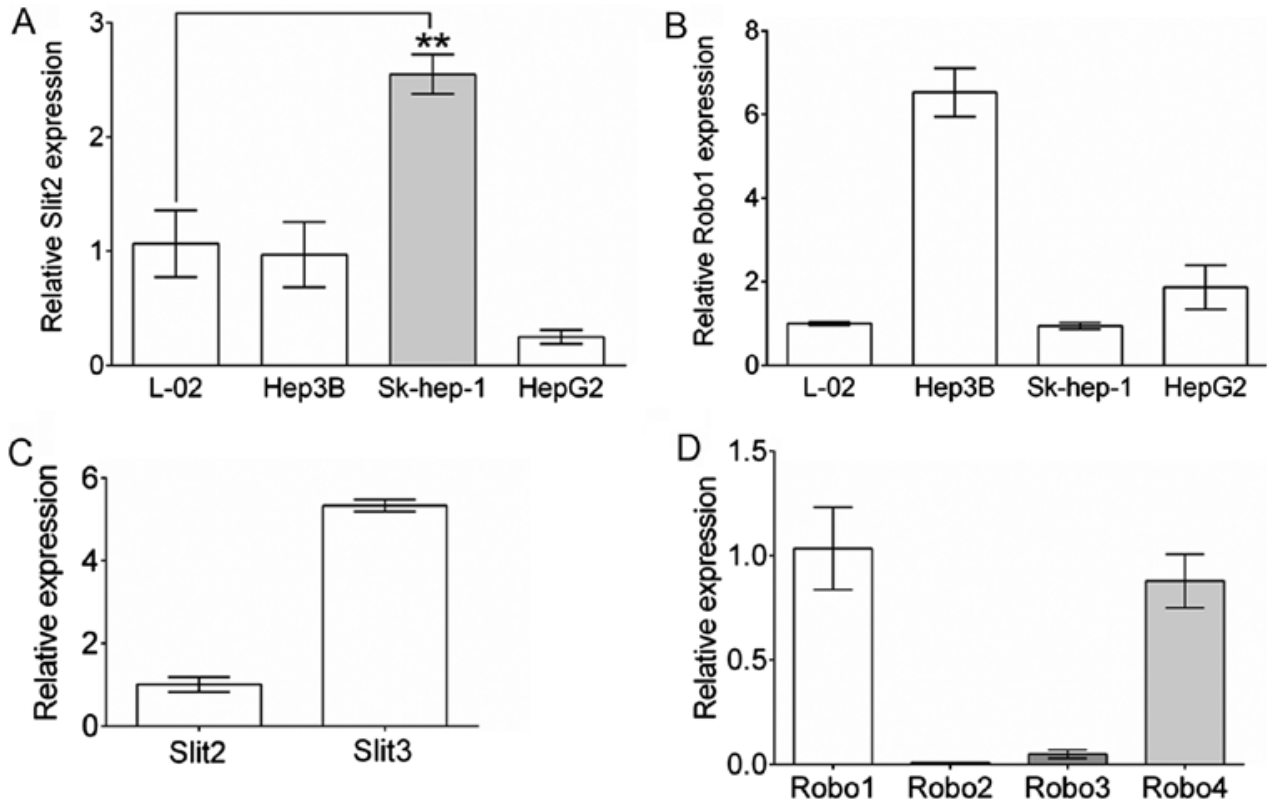

Figure 2. The gene expression of slit and Robo in HCC cell lines. (A) Slit2 and (B) Robol gene expression were examined by real-time qPCR. Data were first normalized to GAPDH and then normalized to the expression level found in L-02 cells. (C) Comparison of Slit2 and Slit3 gene expression in Sk-hep-1 cells. Data were normalized to the value of Slit2. (D) Comparison of Robo 1,2,3 and 4 expression in Sk-hep-1 cells. Data were normalized to the value of Robo1. Each sample was analyzed in triplicate and results are expressed as fold changes. All data are expressed as the mean \pm SEM $\left({ }^{* *} \mathrm{P}<0.01, \mathrm{n}=3\right)$.
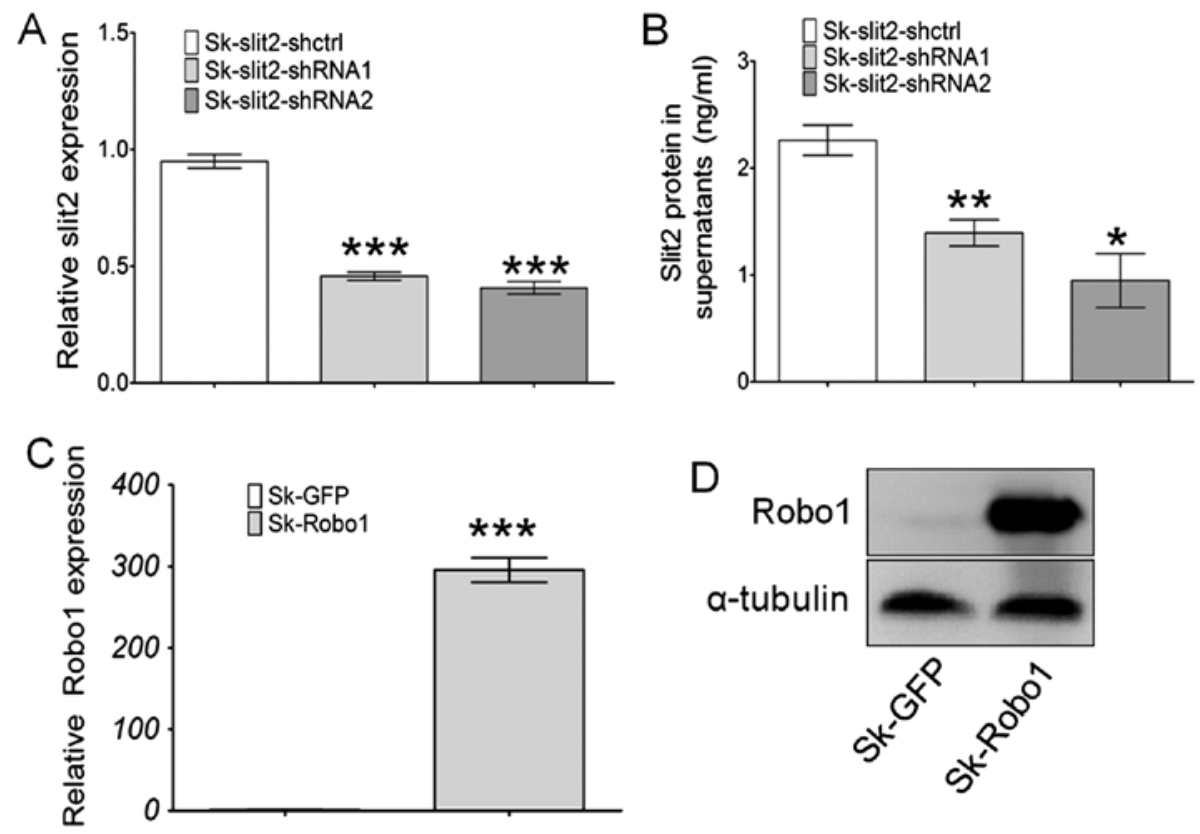

Figure 3. Slit2 knockdown and Robol overexpression in Sk-hep-1 cells. For Slit2 knockdown, Sk-hep-1 cells were stably transduced by pll3.7-Slit2-shRNA (Sk-Slit2-shRNA) or a control plasmid (Sk-Slit2-shctrl) as described in Materials and methods. For Robol overexpression, pBobi-Robol (Sk-Robo1) or control plasmid (Sk-GFP) was transduced into cells. Knockdown of Slit2 expression was analyzed by (A) real-time qPCR and (B) ELISA. Secreted Slit2 production in cell supernatants was measured with a Slit2 ELISA kit. Robo1 overexpression was analyzed by (C) real-time qPCR and (D) western blot analysis. Data are expressed as the mean \pm SEM. Significant differences $\left({ }^{*} \mathrm{P}<0.05,{ }^{* * *} \mathrm{P}<0.01,{ }^{* * * *} \mathrm{P}<0.001, \mathrm{n}=3\right)$ were determined by the Student's t-test using GraphPad Prism 5.0 software.

Slit2 reduced to $1.39 \mathrm{ng} / \mathrm{ml}(\mathrm{n}=3, \mathrm{P}=0.0098), 0.94 \mathrm{ng} / \mathrm{ml}(\mathrm{n}=3$, $\mathrm{P}=0.0105)$ in Sk-Slit2-shRNA1 and shRNA2 cells, respectively (Fig. 3B). Overexpression of Robol in Sk-hep-1 cells induced a nearly 300 -fold increase in mRNA levels (Fig. 3C), this was confirmed at the protein level by western blotting (Fig. 3D). Stable Slit2-knockdown and Robol-overexpressing cell lines were thus generated successfully.
Slit2 knockdown and Robol overexpression promote proliferation and tumor growth of Sk-hep-1 cells. To investigate the effects of Slit2 knockdown and Robol overexpression on the proliferation of Sk-hep-1 cells, an MTT assay was performed. As shown in Fig. 4A, Slit2 knockdown in Sk-hep-1 cells promoted cell proliferation, suggesting an innate role for Slit2 in Sk-hep-1 cells as a tumor suppressor. Contrary 


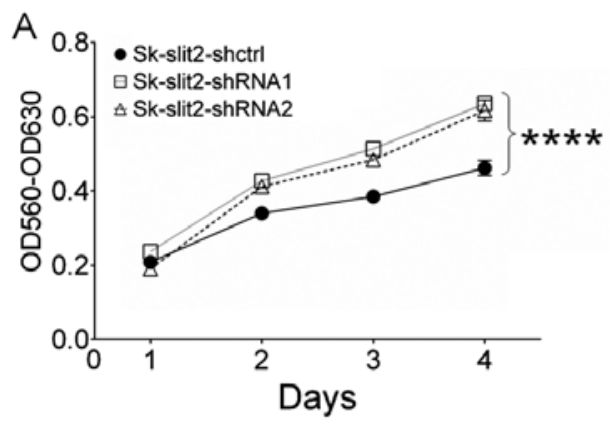

$\mathrm{B}$



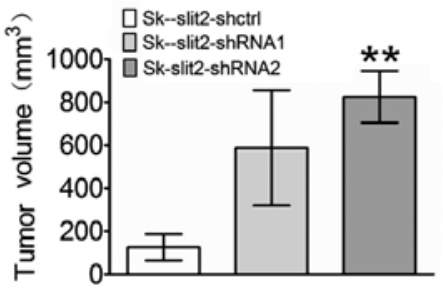

C
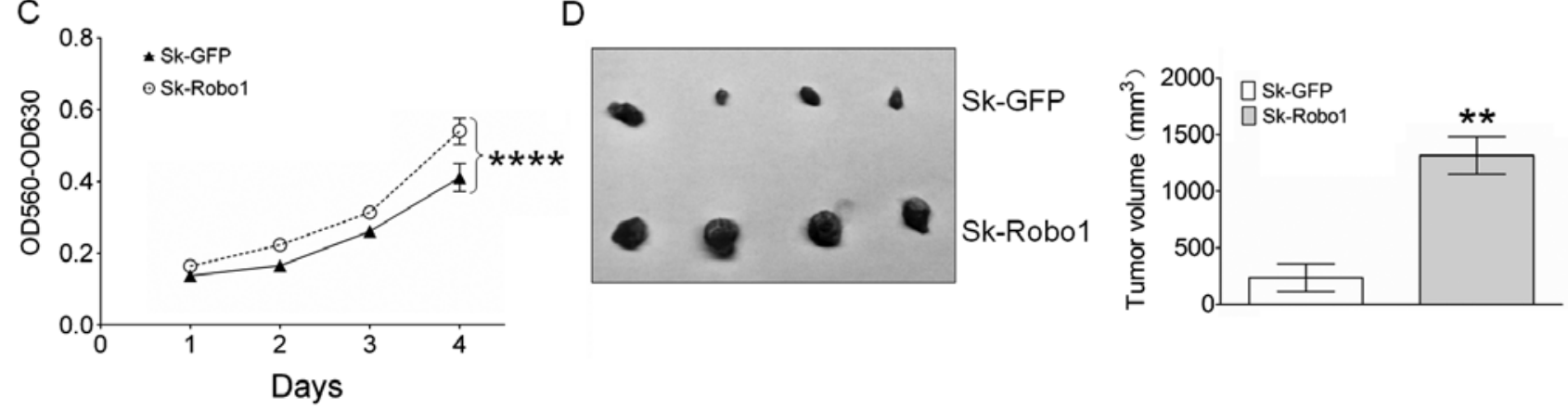

Figure 4. The effects of Slit2 knockdown and Robo1 overexpression on tumor growth. Sk-hep-1 cells were cultured in 96-well microplates for four consecutive days. MTT assays were performed each day to examine the effects of Slit 2 knockdown (A) or Robol overexpression (C) on cell proliferation (n=5). The results are expressed as the mean $\pm \mathrm{SD}$ and significant differences were determined by the two-way analysis of variance $\left(\mathrm{ANOVA},{ }^{* * * *} \mathrm{P}<0.0005\right)$. For the tumor growth assay, cells were inoculated subcutaneously (s.c.) into the right flanks of 4-week-old Balb/c nude mice. The resulting tumors were completely dissected and tumor volumes calculated. Both Slit 2 knockdown $(B, n=3)$ and Robol overexpression $(D, n=4)$ promoted tumor growth. The results are expressed as the mean \pm SD. Significant differences were determined by Student's t-test using GraphPad Prism 5.0 software $\left(^{* *} \mathrm{P}<0.01,{ }^{* * * *} \mathrm{P}<0.001\right)$.

to Slit2, Robol appears to be a tumor promoter, since Robol overexpression in Sk-hep-1 cells resulted in enhanced cell proliferation (Fig. 4C). To test whether the effects of Slit2 and Robol on in vitro cell proliferation can be reproduced in in vivo model, transduced Sk-hep-1 cells were injected into nude mice, and 30 days later tumor volumes measured. As expected, Slit2 knockdown stimulated the growth of Sk-hep-1 tumors (Fig. 4B), although a significant difference in tumor volume was not observed between Sk-Slit2-shctrl $\left(125.6 \pm 61 \mathrm{~mm}^{3}\right)$ and Sk-Slit2-shRNA1 $\left(587.3 \pm 267.3 \mathrm{~mm}^{3}\right.$, $\mathrm{P}=0.168)$ xenografts due to individual differences in mice, a significant increase in tumor volume was observed in Sk-Slit2-shRNA2 tumors $\left(825.7 \pm 120.9 \mathrm{~mm}^{3}, \mathrm{P}=0.0067\right)$ relative to Sk-Slit2-shctrl tumors. Overexpression of Robol in Sk-hep-1 cells also promoted tumor growth. As shown in Fig. 4D, a significant increase in tumor volume was observed in Sk-Robol xenografts $\left(1315 \pm 164.4 \mathrm{~mm}^{3}, \mathrm{P}=0.0015\right)$, when compared to Sk-GFP control xenografts $\left(237.5 \pm 121.7 \mathrm{~mm}^{3}\right)$. These results suggest that Slit2 and Robol exerted opposing effects on HCC proliferation and tumor growth.

Slit2 knockdown and Robol overexpression promote invasion and metastasis of Sk-hep-1 cells. Metastasis is the main cause of death for patients with HCC, with cell migration, and adhesion affecting aspects of tumor metastasis. We examine the effects of Slit2 knockdown and Robol overexpression on tumor metastasis, using both in vitro assays such as cell migration, adhesion and an in vivo intravenous injection of Sk-hep-1 cells for an experimental metastasis assay. As with cellular proliferation and tumor growth, Slit2 and Robol also displayed contrasting functions in aspects of metastasis. Both
Slit2 knockdown and Robol overexpression in Sk-hep-1 cells enhanced cell migration (Fig. 5A and D) and decreased cell adhesion (Fig. 5B and E). The effects of Slit2 knockdown and Robol overexpression on metastasis of Sk-hep-1 cells were observed after the intravenous injection of tumor cells, since all lentiviral pll3.7 vectors for Slit2 knockdown carried a GFP marker, the pulmonary metastasis of cells was conveniently analyzed by directly counting fluorescent metastatic Sk-hep-1 tumor nodules on the surface of lung tissues. Since the pBobi vectors for Robol overexpression did not have a GFP marker, the pulmonary metastasis of cells was determined by counting tumor nodules on lung tissues sections. Slit2 knockdown (Fig. 5C) or Robol overexpression (Fig. 5F) in Sk-hep-1 cells significantly increased the number of metastatic tumor nodules. Therefore, the counter effect of Slit 2 and the effect of Robo1, on tumor metastasis were validated in an in vivo model.

Slit2 knockdown induces upregulation of Robol expression. An inverse correlation between Slit 2 and Robol expression has recently been reported (25-27). To investigate the effects of Slit2 knockdown on Robol expression, qPCR and western blot analysis were performed. As shown in Fig. 6, Slit2 knockdown induced the upregulation of Robol at both the mRNA and protein level. Given the stimulatory effects of Robol overexpression on tumor growth and metastasis, the observation that Slit2 knockdown promoted tumor growth and metastasis of Sk-hep-1 cells could be partly ascribed to the upregulation of Robo1.

Robol overexpression increases MMP2, -9 and decreases TIMP1, -2 expression through different signaling pathways. 


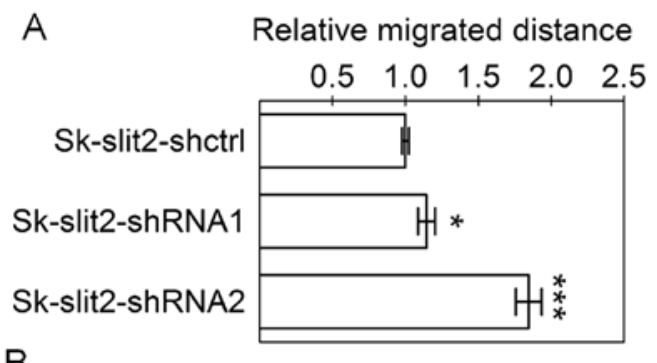

B

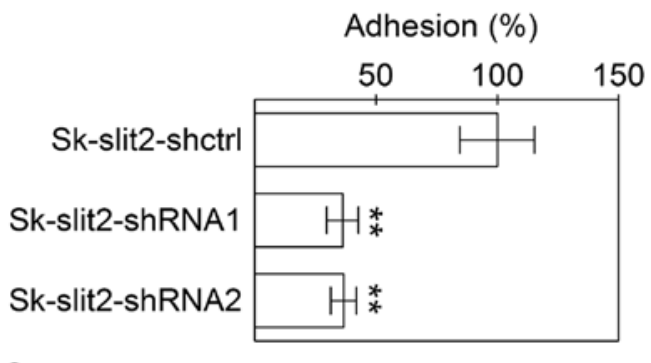

C
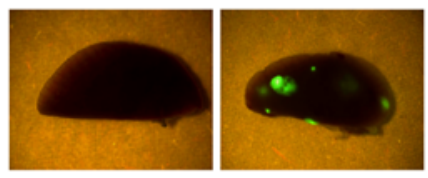

Sk-slit2 -shctrl

\section{Sk-slit2}

-shRNAl

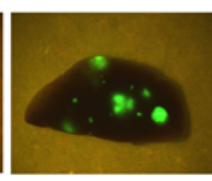

Metastatic lung nodules

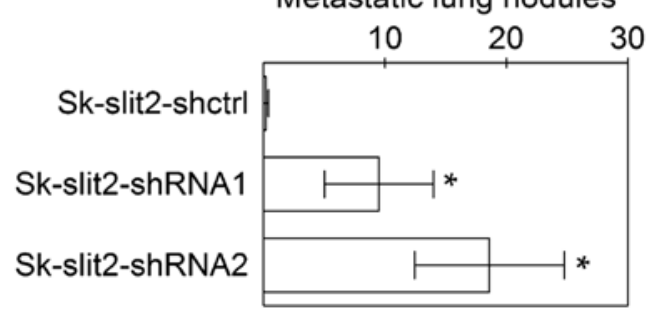

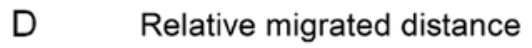

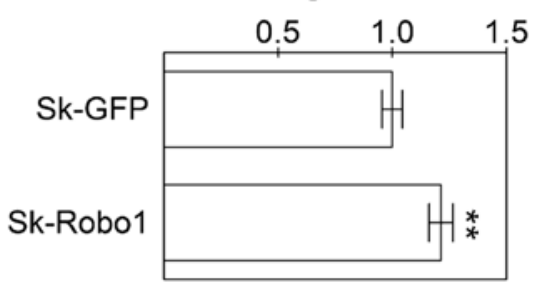

$E$

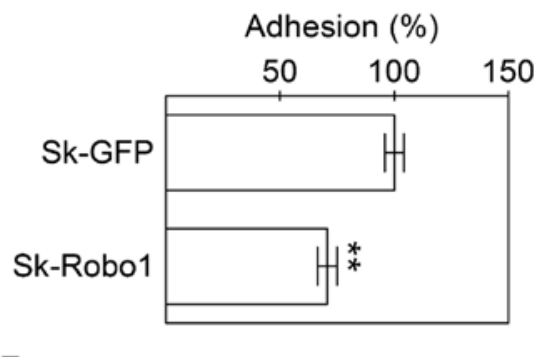

F
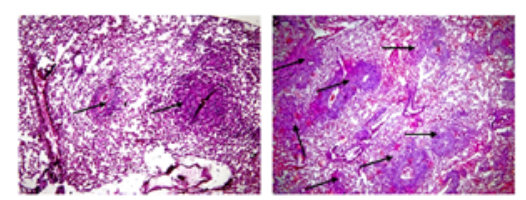

Sk-GFP

Sk-Robol

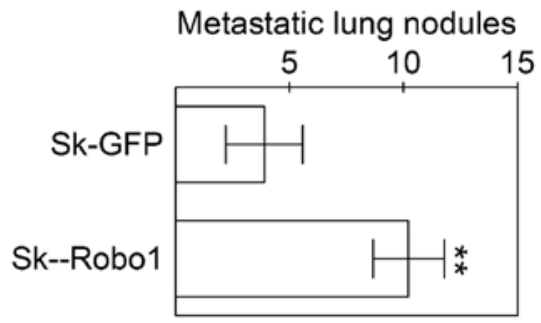

Figure 5. The effects of Slit2 knockdown and Robol overexpression on tumor metastasis. Migration and adhesion assays were performed as described in Materials and methods. Both Slit2 knockdown and Robol overexpression promoted cell migration (A and D, respectively, $\mathrm{n}=3$ ) and suppressed cell adhesion (B and $\mathrm{E}$, respectively, n=4). For tumor metastasis, Slit2-shRNA, Robo1 and control transduced stable Sk-hep-1 cell lines were injected intravenously. Metastatic tumor nodules in all lung lobes were counted either under a fluorescence microscope directly. Original magnification, x40 (C) or in paraffin sections x200 (F). Results are expressed as the mean \pm SD. Significant differences were determined by Student's t-test using GraphPad Prism 5.0 software $\left({ }^{*} \mathrm{P}<0.05,{ }^{* *} \mathrm{P}<0.01,{ }^{* * *} \mathrm{P}<0.001\right)$.
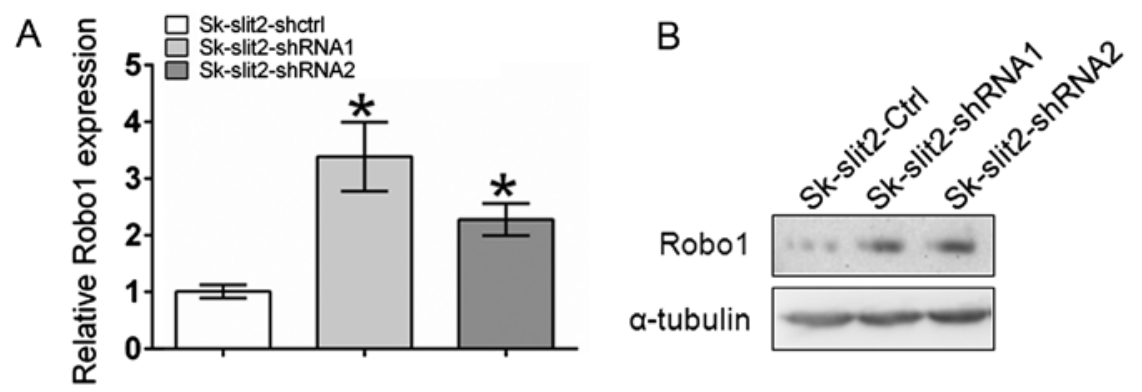

Figure 6. Slit2 knockdown upregulated Robol expression. RNA and protein samples were purified from confluent Sk-hep-1 cells and (A) real-time qPCR and (B) western blot analysis was performed.

Most MMPs are secreted as inactive proenzymes whose activities are tightly regulated by mRNA transcription and stability control, and proenzyme activation via their activators and inhibitors. MT1-MMP (MMP14, activator), and TIMP1 and -2 (inhibitors) are key molecules for pro-MMPs activation. To explore the underlying correlations between Robol overexpression and MMPs, the expression of several secreted MMPs and TIMP1, -2 was examined by RT-PCR. As shown in Fig. 7A, 
A

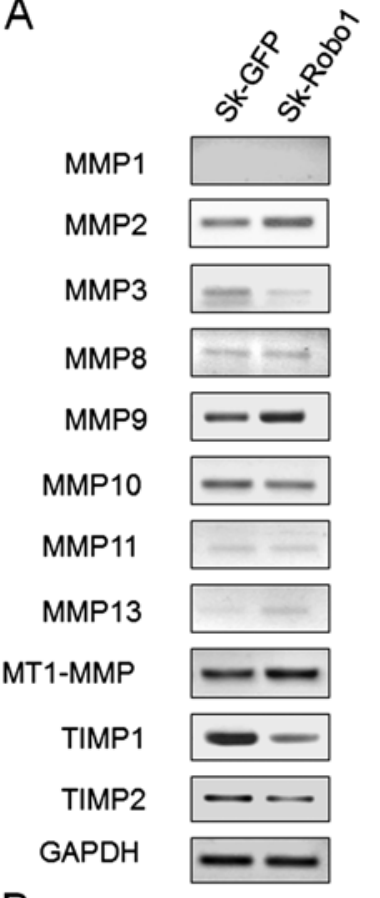

$B$

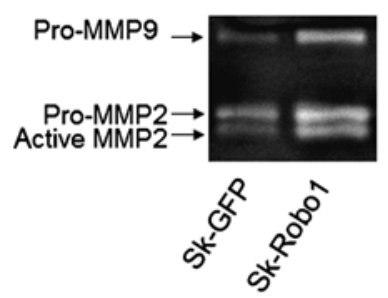



D

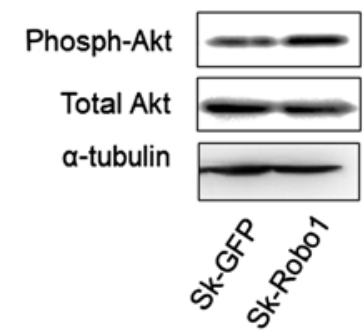

Figure 7. Robol overexpression stimulated expression of MMP2 and 9 and the activation of MMP2, but not MMP9, through a PI3k/Akt signaling pathway. (A) RT-PCR. Expression of MMP2 and 9 and MT1-MMP was upregulated and TIMP1 and 2 expression was downregulated in Sk-Robol cells. (B) Gelatin zymography. Robol overexpression stimulated the activation of MMP2, but not MMP9. (C) RT-PCR. Three MAPK inhibitors $(10 \mu \mathrm{M}$ SB203580 for p38 blockage, $20 \mu \mathrm{M}$ PD98059 for ERK blockage, and $10 \mu \mathrm{M}$ SP600125 for JNK blockage) and a PI3K inhibitor (10 $\mu \mathrm{M}$ LY294002) were added to the culture medium of Sk-hep-1 cells, RT-PCR was performed 24 h later. LY294002 significantly suppressed MMP2 expression, indicating the importance of the PI3k/Akt signaling pathway in regulating MMP2 expression. (D) Western blot analysis. Robol overexpression stimulated the phosphorylation of Akt.

MMP2, -9 and MT1-MMP expression were upregulated, and TIMP1 and 2 expression were downregulated in Robol overexpressing Sk-hep-1 cells. Other MMPs, except MMP10, were either not detected or detected in minute quantities, suggesting MMP2 and 9 to be the key secreted MMPs involved in the metastasis of these cells. As a pro-MMP activity assay, gelatin zymography was performed. Robol overexpression increased the production of pro-MMP2 and 9, and induced pro-MMP2, but not pro-MMP9, activation (Fig. 7B).

Robol overexpression stimulated the phosphorylation of Akt. The MAPK (28-30) and PI3k/Akt (31-33) signaling pathways have been widely reported to be involved in regulating the expression of MMPs in HCC. To determine whether the alteration in MMP and TIMP expression induced by Robol overexpression in Sk-hep-1 cells was mediated by these two signaling pathways, three MAPK inhibitors (SB203580 for
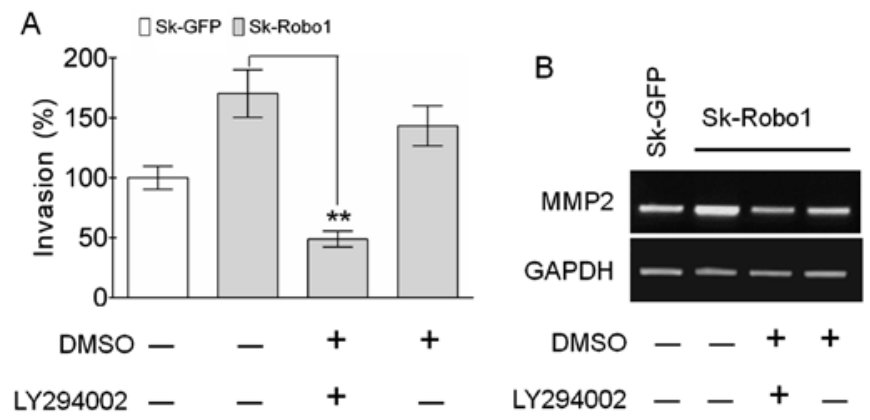

Figure 8. LY294002 antagonizes the enhancement of cell invasion and MMP2 expression induced by Robol overexpression. (A) Matrigel invasion assay. A total of $1 \times 10^{4}$ cells/chamber in $100 \mu 1$ serum-free DMEM were plated on the upper Matrigel-coated chambers. LY294002 dissolved in DMSO was added to the medium in the lower chambers. After incubation, the invaded cells on the lower surface were counted $\left({ }^{* *} \mathrm{P}<0.01, \mathrm{n}=3\right)$. (B) LY294002 was added to the culture medium of Sk-Robol cells. RT-PCR was performed $24 \mathrm{~h}$ later.

p38 blockage, PD98059 for ERK blockage, and SP600125 for JNK blockage) and a PI3k inhibitor (LY294002) were used to block the corresponding signal transduction pathways. The expression of MMPs and TIMPs was assayed by RT-PCR. As shown in Fig. 7C, LY294002 significantly inhibited MMP2 expression. SB203580 inhibited MMP9 and PD98059 inhibited MMP2 and 9 expression slightly. Significant changes were not observed in TIMPs expression upon inhibitor treatment (Fig. 7C). This suggested that varied signaling pathways for the modulation of MMP2 and 9 expression exist in cells. It was observed that $\mathrm{p} 38$ MAPK only slightly affected MMP2 expression, and that ERK MAPK slightly affected MMP9. The PI3k/ Akt signaling pathway, however, significantly affected MMP2 expression. Combined with the observation that Robol overexpression stimulated the phosphorylation of Akt (Fig. 7D), we postulated that the PI3K/Akt signaling pathway mediates Robol-induced metastasis of Sk-hep-1 cells, at least partly, by upregulating MMP2.

LY294002 antagonizes the enhancement of cell invasion and MMP 2 expression induced by Robol overexpression. To test the theory that the PI3k/Akt signaling pathway is involved in metastasis of Sk-hep-1 cells, the effects of LY294002 on in vitro tumor invasion were examined. As shown in Fig. 8A, LY294002 neutralized the enhanced invasive ability of Sk-hep-1 cells induced by Robol overexpression, concomitant with blocking the upregulation of MMP2 (Fig. 8B). These results confirmed the crucial role of the PI3k/Akt signaling pathway in Robol-mediated tumor metastasis.

\section{Discussion}

Reduced Slit2 expression has been reported in a great variety of cancers, and is predominantly due to the hypermethylation of the Slit2 promoter (34-39). Although Slit2 downregulation has also been reported in HCC tissues (21), large-scale mining of microarray data from the Oncomine database revealed a heterogeneous expression pattern for Slit2 in HCC clinical samples (Fig. 1A). Conversely, expression of the Slit2 cognate receptor, Robol, is aberrantly upregulated in HCC samples (Fig. 1B). Interestingly, a negative regulatory loop between 
Slit2 and Robol mediated by $m i R-218$, which targets the $3^{\prime}$ untranslated region (3'UTR) of Robol and resides in the intron of the Slit 2 genome, has recently been confirmed (25-27). The significance of the negative regulatory loop is still elusive. In the present study, a similar inverse correlation between Slit2 and Robol was found in Sk-hep-1, which maintain a high level of Slit2 and a low level of Robol, and in Hep3B and HepG2 cells, which maintain a high level of Robol but a low level of Slit2 (Fig. 2A and B). Notably, we found, Slit2 knockdown led to the upregulation of Robol (Fig. 6). As the target of RNA knockdown is a final sliced Slit2 $m R N A$, not a genomic Slit2 sequence, effects are not exerted on the $m i R-218$ localized within an intron. Thus, the upregulation of Robol caused by Slit 2 knockdown is presumed to be via an as yet unknown mechanism distinct from one that is miR-218 mediated. We examined the functions of Slit 2 and Robol by knockdown of Slit 2 or by overexpression of Robol, respectively, in Sk-hep-1 cells. Unexpectedly, these alteration in Slit2 and Robol expression induced opposing effects on tumor growth and metastasis.

Though still controversial, reports on the inhibitory effects of Slit 2 on the progression of various tumors are more numerous than those describing its stimulatory effects. The effects of the Slit2/Robol signaling axis in HCC, however, have rarely been studied. Jin et al (21) reported that adenovirus mediated Slit2 overexpression in an SMMC-7721 cell line suppressed cell growth, migration and invasion. However, the author did not state whether the suppressive effects of Slit2 were mediated by the Robol receptor. Our results strengthened the above (21) findings by further providing evidence that lentivirusmediated Slit2 knockdown in Sk-hep-1 cells, promoted cell proliferation, highlighting the potential tumor suppressor role of Slit2 in cells. Moreover, Robol overexpression in Sk-hep-1 cells also promoted cell proliferation. These results were also confirmed in our tumor xenograft model, suggesting Slit2 and Robol induce opposing effects on tumor growth (Fig. 4).

Cell migration, adhesion and invasion are closely associated with tumor metastasis. Weakened cell adhesion, and enhanced cell migration and invasion, are characteristics of metastatic tumor cells. We found, both Slit2 knockdown and Robol overexpression in Sk-hep-1 cells promoted tumor metastasis, concomitant with decreased cell adhesion and enhanced migration, indicating Slit2 and Robo1 induce opposing effects on tumor metastasis (Fig. 5).

MMPs are critical participants in degrading the extracellular matrix to pave the way for tumor metastasis, of which MMP2 and 9 are key molecules due to their unique ability to degrade type IV collagens, major components of the basement membrane. Notably, MMP2 and 9 are secreted as latent proenzymes whose activities rely on proteolytic activation. TIMP1 and 2 are inhibitors of MMP activation, with MT1-MMP a specific activator of MMP2 activation. The balance between MT1-MMP and TIMP2 determines MMP2 activation. The activation of MMP9 is more complex, as many molecules, including MMP2, are involved in this process (40). We found that only MMP2, -9 and regulators of their activity such as MT1-MMP and TIMP1 and 2 were dominantly expressed in Sk-hep-1 cells, suggesting the alterations of MMP2 and -9 expression and their activities are important for cellular metastasis. Robol overexpression stimulated MMP2, -9 and MT1-MMP, but suppressed expression of TIMPI and 2, thereby promoting the activation of MMP2, but not MMP9, and causally resulted in the promotion of tumor metastasis (Fig. 7A and B).

The expression of MMP2 and 9 is regulated heterogeneously by different signaling pathways in HCC tissues (41-43). We found that MMP2, but not MMP9, was regulated by the PI3K/Akt signaling pathway (Fig. 7C). Robol overexpression enhanced the phosphorylation of Akt and SK-hep-1 cell invasion which was antagonized by PI3K-specific inhibitor, LY294002 (Figs. 7D and 8). This led us to postulate that Robo1 promoted tumor invasion partly by the upregulation of MMP2 after activating the PI3K/Akt signaling pathway. These results strengthened the importance place on the PI3K/Akt signaling pathway in the metastasis of HCC as frequently reported by others (31-33).

From results reported to date, the confirmed involvement of the Slit2/Robol signaling pathway on tumor progression either induces inhibitory or stimulatory effects. In our experiments, the effects of Slit2 knockdown in Sk-hep-1 cells suggested a negative role for Slit2 in tumor metastasis, whereas Robol overexpression in Sk-hep-1 cells pointed to a positive role for Robol in tumor metastasis. As a result, a question arises: how does the Robol receptor, which plays a positive role on tumor metastasis, mediate the negative effects of Slit2 in tumor metastasis if the Slit2/Robol signaling axis mediates the effects observed in Sk-hep-1 cells? Although we did not explore the exact mechanisms for the contrasting effects of Slit2 and Robo1 on HCC growth and metastasis, the observation that Slit2 knockdown caused the upregulation of Robol expression provides an indication to the possible mechanism. Basically, the Slit2/Robol signaling axis induces suppressive effects on HCC metastasis, while the knockdown of Slit2 removes the suppressive effects, resulting in the enhancement of the metastasis. Furthermore, the upregulation of Robo1 induced by Slit 2 knockdown might induce stimulatory effects upon the binding of other Slit ligands such as Slit3. We found that, while Sk-hep-1 cells maintained a relatively high expression of Slit2 and low expression of Robol compared levels in with normal cells, an even higher expression of Slit3 was detected (Fig. 1C). Our previous study demonstrated that Slit3 knockdown promoted proliferation, migration and invasion of A549 cells, indicating a tumor suppressor role for Slit3 in lung adenocarcinoma (20). However, the effects of Slit 3 might depend on either the Robo receptors it interacts with, or the cell context. Among the four members of Robo receptors, Robo4 is structurally distinct from the others, indicating it may be involved in signaling differently to that of Robol. The Slit3/Robo4 signaling pathway has been shown to play a proangiogenic role in embryonic angiogenesis (44) and human engineered tissues (45). In Sk-hep-1 cells, Robo4 was second in expression to Robol, although at a low level (Fig. 1D). Whether Slit3 can induce the stimulatory effects on tumor metastasis by binding to Robol that has been upregulated by Slit2 knockdown or to Robo4, deserves further study.

In summary, our results provide evidence that Slit 2 and Robol induce opposing effects on tumor growth and metastasis. Slit2 knockdown and Robol overexpression in Sk-hep-1 cells promotes tumor growth and metastasis, suggesting a negative and positive role for Slit2 and Robol, respectively, in tumor progression. These results contradict published reports 
to date that indicate the Slit2/Robol signaling axis induces either a suppressive or stimulatory effect on tumor progression. Our finding that Slit2 knockdown leads to the upregulation of Robo1, presumably not mediated by $m i R-218$, provides a potential new mechanism for these contradictory results.

\section{Acknowledgements}

The present study was supported by Grants by the National Natural Science Foundation of China (grant nos. 30971210 and 30671021) and the Key Project of Chinese Ministry of Education (grant no. 109093).

\section{References}

1. Mommersteeg MT, Yeh ML, Parnavelas JG and Andrews WD Disrupted Slit-Robo signalling results in membranous ventricular septum defects and bicuspid aortic valves. Cardiovasc Res 106: 55-66, 2015.

2. Weyers JJ, Milutinovich AB, Takeda Y, Jemc JC and Van Doren M: A genetic screen for mutations affecting gonad formation in Drosophila reveals a role for the slit/robo pathway. Dev Biol 353: 217-228, 2011.

3. Dickinson RE, Hryhorskyj L, Tremewan H, Hogg K, Thomson AA, McNeilly AS and Duncan WC: Involvement of the SLIT/ROBO pathway in follicle development in the fetal ovary. Reproduction 139: 395-407, 2010.

4. Piper M, Georgas K, Yamada T and Little M: Expression of the vertebrate Slit gene family and their putative receptors, the Robo genes, in the developing murine kidney. Mech Dev 94: 213-217, 2000.

5. Chang PH, Hwang-Verslues WW, Chang YC, Chen CC Hsiao M, Jeng YM, Chang KJ, Lee EY, Shew JY and Lee WH: Activation of Robo1 signaling of breast cancer cells by Slit2 from stromal fibroblast restrains tumorigenesis via blocking PI3K/Akt//-catenin pathway. Cancer Res 72: 4652-4661, 2012.

6. Marlow R, Strickland P, Lee JS, Wu X, Pebenito M, Binnewies M, Le EK, Moran A, Macias H, Cardiff RD, et al: SLITs suppress tumor growth in vivo by silencing Sdf1/Cxcr4 within breast epithelium. Cancer Res 68: 7819-7827, 2008.

7. Göhrig A, Detjen KM, Hilfenhaus G, Körner JL, Welzel M, Arsenic R, Schmuck R, Bahra M, Wu JY, Wiedenmann B, et al: Axon guidance factor SLIT2 inhibits neural invasion and metastasis in pancreatic cancer. Cancer Res 74: 1529-1540, 2014.

8. Mano Y, Aishima S, Fukuhara T, Tanaka Y, Kubo Y, Motomura T, Toshima T, Iguchi T, Shirabe K, Maehara Y, et al: Decreased roundabout 1 expression promotes development of intrahepatic cholangiocarcinoma. Hum Pathol 44: 2419-2426, 2013.

9. Werbowetski-Ogilvie TE, Seyed Sadr M, Jabado N, AngersLoustau A, Agar NY, Wu J, Bjerkvig R, Antel JP, Faury D, Rao Y, et al: Inhibition of medulloblastoma cell invasion by Slit. Oncogene 25: 5103-5112, 2006.

10. Mertsch S, Schmitz N, Jeibmann A, Geng JG, Paulus W and Senner V: Slit 2 involvement in glioma cell migration is mediated by Robo1 receptor. J Neurooncol 87: 1-7, 2008.

11. Xu Y, Li WL, Fu L, Gu F and Ma YJ: Slit2/Robo1 signaling in glioma migration and invasion. Neurosci Bull 26: 474-478, 2010.

12. Yiin JJ, Hu B, Jarzynka MJ, Feng H, Liu KW, Wu JY, Ma HI and Cheng SY: Slit2 inhibits glioma cell invasion in the brain by suppression of Cdc42 activity. Neuro Oncol 11: 779-789, 2009.

13. Zhang QQ, Zhou DL, Lei Y, Zheng L, Chen SX, Gou HJ, Gu QL, He XD, Lan T, Qi CL, et al: Slit2/Robo1 signaling promotes intestinal tumorigenesis through Src-mediated activation of the Wnt/ $\beta$-catenin pathway. Oncotarget 6: 3123-3135, 2015.

14. Zhou WJ, Geng ZH, Chi S, Zhang W, Niu XF, Lan SJ, Ma L, Yang X, Wang LJ, Ding YQ, et al: Slit-Robo signaling induces malignant transformation through Hakai-mediated E-cadherin degradation during colorectal epithelial cell carcinogenesis. Cell Res 21: 609-626, 2011.

15. Yang XM, Han HX, Sui F, Dai YM, Chen M and Geng JG: Slit-Robo signaling mediates lymphangiogenesis and promotes tumor lymphatic metastasis. Biochem Biophys Res Commun 396: 571-577, 2010.
16. Wang LJ, Zhao Y, Han B, Ma YG, Zhang J, Yang DM, Mao JW, Tang FT, Li WD, Yang Y, et al: Targeting Slit-Roundabout signaling inhibits tumor angiogenesis in chemical-induced squamous cell carcinogenesis. Cancer Sci 99: 510-517, 2008.

17. Qi C, Lan H, Ye J, Li W, Wei P, Yang Y, Guo S, Lan T, Li J, Zhang Q, et al: Slit2 promotes tumor growth and invasion in chemically induced skin carcinogenesis. Lab Invest 94: 766-776, 2014.

18. Xiao R, Zhao Y, Wang LJ and Li WP: Effects of Roundabout 5 on adhesion, invasion and potential motility of human tongue carcinoma Tb cells. Chin Med J (Engl) 124: 2367-2371, 2011.

19. Prasad A, Fernandis AZ, Rao Y and Ganju RK: Slit proteinmediated inhibition of CXCR4-induced chemotactic and chemoinvasive signaling pathways in breast cancer cells. J Biol Chem 279: 9115-9124, 2004.

20. Zhang C, Guo H, Li B, Sui C, Zhang Y, Xia X, Qin Y, Ye L, Xie $\mathrm{F}$, Wang $\mathrm{H}$, et al: Effects of Slit3 silencing on the invasive ability of lung carcinoma A549 cells. Oncol Rep 34: 952-960, 2015.

21. Jin J, You H, Yu B, Deng Y, Tang N, Yao G, Shu H, Yang S and Qin W: Epigenetic inactivation of SLIT2 in human hepatocellular carcinomas. Biochem Biophys Res Commun 379: 86-91, 2009.

22. Wurmbach E, Chen YB, Khitrov G, Zhang W, Roayaie S, Schwartz M, Fiel I, Thung S, Mazzaferro V, Bruix J, et al: Genome-wide molecular profiles of HCV-induced dysplasia and hepatocellular carcinoma. Hepatology 45: 938-947, 2007.

23 Mas VR, Maluf DG, Archer KJ, Yanek K, Kong X, Kulik L, Freise CE, Olthoff KM, Ghobrial RM, McIver P, et al: Genes involved in viral carcinogenesis and tumor initiation in hepatitis C virus-induced hepatocellular carcinoma. Mol Med 15: 85-94, 2009.

24. Roessler S, Jia HL, Budhu A, Forgues M, Ye QH, Lee JS, Thorgeirsson SS, Sun Z, Tang ZY, Qin LX, et al: A unique metastasis gene signature enables prediction of tumor relapse in early-stage hepatocellular carcinoma patients. Cancer Res 70: 10202-10212, 2010.

25. Tie J, Pan Y, Zhao L, Wu K, Liu J, Sun S, Guo X, Wang B, Gang Y,Zhang Y, et al: MiR-218 inhibits invasion and metastasis of gastric cancer by targeting the Robol receptor. PLoS Genet 6: e1000879, 2010.

26. Alajez NM, Lenarduzzi M, Ito E, Hui AB, Shi W, Bruce J, Yue S, Huang $\mathrm{SH}, \mathrm{Xu} \mathrm{W}$, Waldron J, et al: MiR-218 suppresses nasopharyngeal cancer progression through downregulation of survivin and the SLIT2-ROBO1 pathway. Cancer Res 71: 2381-2391, 2011.

27. Gu JJ, Gao GZ and Zhang SM: miR-218 inhibits the migration and invasion of glioma U87 cells through the Slit2-Robo1 pathway. Oncol Lett 9: 1561-1566, 2015.

28. Cho SB, Park YL, Park SJ, Park SY, Lee WS, Park CH, Choi SK, Heo YH, Koh YS, Cho CK, et al: KITENIN is associated with activation of AP-1 target genes via MAPK cascades signaling in human hepatocellular carcinoma progression. Oncol Res 19: 115-123, 2011.

29. Huang X, Huang S, Zhang F, Han X, Miao L, Liu Z, Fan Z and Ji G: Lentiviral-mediated Smad4 RNAi promotes SMMC-7721 cell migration by regulation of MMP-2, VEGF and MAPK signaling. Mol Med Rep 3: 295-299, 2010.

30. Zhu B, Shi S, Ma YG, Fan F and Yao ZZ: Lysophosphatidic acid enhances human hepatocellular carcinoma cell migration, invasion and adhesion through P38 MAPK pathway. Hepatogastroenterology 59: 785-789, 2012.

31. Chen JS, Wang Q, Fu XH, Huang XH, Chen XL, Cao LQ, Chen LZ, Tan HX, Li W, Bi J, et al: Involvement of PI3K/PTEN/ $\mathrm{AKT} / \mathrm{mTOR}$ pathway in invasion and metastasis in hepatocellular carcinoma: Association with MMP-9. Hepatol Res 39: 177-186, 2009.

32. Li X, Yang Z, Song W, Zhou L, Li Q, Tao K, Zhou J, Wang X, Zheng Z, You N, et al: Overexpression of Bmi-1 contributes to the invasion and metastasis of hepatocellular carcinoma by increasing the expression of matrix metalloproteinase (MMP)-2, MMP-9 and vascular endothelial growth factor via the PTEN/ PI3K/Akt pathway. Int J Oncol 43: 793-802, 2013.

33. Xu J, Jia L, Ma H, Li Y, Ma Z and Zhao Y: Axl gene knockdown inhibits the metastasis properties of hepatocellular carcinoma via PI3K/Akt-PAK1 signal pathway. Tumour Biol 35: 3809-3817, 2014.

34. Maiti GP, Ghosh A, Mondal P, Ghosh S, Chakraborty J, Roy A, Roychowdhury $\mathrm{S}$ and Panda CK: Frequent inactivation of SLIT2 and ROBO1 signaling in head and neck lesions: Clinical and prognostic implications. Oral Surg Oral Med Oral Pathol Oral Radiol 119: 202-212, 2015. 
35. Nones K1, Waddell N, Song S, Patch AM, Miller D, Johns A, Wu J, Kassahn KS, Wood D, Bailey P, et al: Genome-wide DNA methylation patterns in pancreatic ductal adenocarcinoma reveal epigenetic deregulation of SLIT-ROBO, ITGA2 and MET signaling. Int J Cancer 135: 1110-1118, 2014.

36. Ma WJ, Zhou Y, Lu D, Dong D, Tian XJ, Wen JX and Zhang J: Reduced expression of Slit2 in renal cell carcinoma. Med Oncol 31: 768, 2014.

37. Kim GE1, Lee KH, Choi YD, Lee JS, Lee JH, Nam JH, Choi C, Park MH and Yoon JH: Detection of Slit2 promoter hypermethylation in tissue and serum samples from breast cancer patients. Virchows Archiv 459: 383-390, 2011.

38. Dunwell TL, Dickinson RE, Stankovic T, Dallol A, Weston V, Austen B, Catchpoole D, Maher ER and Latif F: Frequent epigenetic inactivation of the SLIT2 gene in chronic and acute lymphocytic leukemia. Epigenetics 4: 265-269, 2009.

39. Dallol A, Krex D, Hesson L, Eng C, Maher ER and Latif F: Frequent epigenetic inactivation of the SLIT2 gene in gliomas. Oncogene 22: 4611-4616, 2003.

40. Toth M, Chvyrkova I, Bernardo MM, Hernandez-Barrantes S and Fridman R: Pro-MMP-9 activation by the MT1-MMP/MMP-2 axis and MMP-3: Role of TIMP-2 and plasma membranes. Biochem Biophys Res Commun 308: 386-395, 2003.
41. Chung TW, Lee YC and Kim CH: Hepatitis B viral HBx induces matrix metalloproteinase-9 gene expression through activation of ERK and PI-3K/AKT pathways: Involvement of invasive potential. FASEB J 18: 1123-1125, 2004.

42. Chen F, Deng J, Liu X, Li W and Zheng J: HCRP-1 regulates cell migration and invasion via EGFR-ERK mediated up-regulation of MMP-2 with prognostic significance in human renal cell carcinoma. Sci Rep 5: 13470, 2015.

43 Cheng JC, Chou CH, Kuo ML and Hsieh CY: Radiationenhanced hepatocellular carcinoma cell invasion with MMP-9 expression through PI3K/Akt/NF-kappaB signal transduction pathway. Oncogene 25: 7009-7018, 2006.

44. Zhang B, Dietrich UM, Geng JG, Bicknell R, Esko JD and Wang L: Repulsive axon guidance molecule Slit3 is a novel angiogenic factor. Blood 114: 4300-4309, 2009.

45. Paul JD, Coulombe KL, Toth PT, Zhang Y, Marsboom G, Bindokas VP, Smith DW, Murry CE and Rehman J: SLIT3ROBO4 activation promotes vascular network formation in human engineered tissue and angiogenesis in vivo. J Mol Cell Cardiol 64: 124-131, 2013. 